\title{
Sexual function after voluntary medical male circumcision for human immunodeficiency virus prevention: Results from a programmatic delivery setting in Botswana
}

\begin{tabular}{|c|c|}
\hline $\begin{array}{l}\text { Authors: } \\
\text { Jillian C. Pinty } \\
\text { Kathleen E. W } \\
\text { Conrad Ntsua } \\
\text { Nora J. Kleinm } \\
\text { Lisa Spees } \\
\text { Bazghina-wer } \\
\text { Shreshth Mau } \\
\text { Jenny Ledikwe }\end{array}$ & 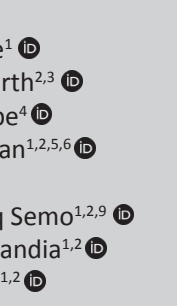 \\
\hline \multicolumn{2}{|c|}{$\begin{array}{l}\text { Affiliations: } \\
{ }^{1} \text { Department of Global Hea } \\
\text { University of Washington, } \\
\text { Seattle, United States }\end{array}$} \\
\hline \multicolumn{2}{|c|}{$\begin{array}{l}{ }^{2} \text { Botswana International } \\
\text { Training and Education } \\
\text { Center for Health (I-TECH), } \\
\text { Gaborone, Botswana }\end{array}$} \\
\hline \multicolumn{2}{|c|}{$\begin{array}{l}{ }^{3} \text { Department of Biostatistics, } \\
\text { Harvard T.H. Chan School of } \\
\text { Public Health, Boston, } \\
\text { Massachusetts, United States }\end{array}$} \\
\hline \multicolumn{2}{|c|}{$\begin{array}{l}{ }^{4} \text { Department of HIV/AIDS } \\
\text { Prevention and Care, } \\
\text { Botswana Ministry of } \\
\text { Health and Wellness, } \\
\text { Gaborone, Botswana }\end{array}$} \\
\hline \multicolumn{2}{|c|}{$\begin{array}{l}{ }^{5} \text { NJK Consulting, Seattle, } \\
\text { Washington, United States }\end{array}$} \\
\hline \multicolumn{2}{|c|}{$\begin{array}{l}{ }^{6} \text { Amgen Asia Holdings Ltd, } \\
\text { Hong Kong, Japan }\end{array}$} \\
\hline \multicolumn{2}{|c|}{$\begin{array}{l}{ }^{7} \text { Department of Health Policy } \\
\text { and Management, University } \\
\text { of North Carolina, Chapel Hill, } \\
\text { United States, }\end{array}$} \\
\hline \multicolumn{2}{|c|}{$\begin{array}{l}{ }^{8} \text { Lineberger Comprehensive } \\
\text { Cancer Center, University of } \\
\text { North Carolina, Chapel Hill, } \\
\text { United States }\end{array}$} \\
\hline \multicolumn{2}{|c|}{$\begin{array}{l}{ }^{9} \mathrm{FHI} 360 \text {, Washington, } \\
\text { Washington, United States }\end{array}$} \\
\hline \multicolumn{2}{|l|}{ Read online: } \\
\hline 回的回 & $\begin{array}{l}\text { Scan this QR } \\
\text { code with your } \\
\text { smart phone or } \\
\text { mobile device } \\
\text { to read online. }\end{array}$ \\
\hline
\end{tabular}

\begin{abstract}
Background: Uptake of voluntary medical male circumcision (VMMC) remains modest in Botswana in spite of the government's commitment and service provision availability. Data on sexual function post-VMMC in programmatic settings could help guide messaging tailored to Botswana.
\end{abstract}

Objectives: At 3-month post-VMMC, we evaluated changes in sexual function and satisfaction with the VMMC procedure amongst a cohort of HIV-negative, sexually active men aged 18-49 years who underwent VMMC in a public-sector clinic in Botswana.

Methods: We assessed whether each of the following domains of sexual function had improved, stayed the same or worsened since VMMC: sexual desire, ability to use condoms, ease of vaginal penetration, ease of ejaculation, ability to achieve and maintain an erection and hygiene or cleanliness.

Results: Data on sexual function were available for 378 men at 3-month post-VMMC. Median age was 27 years $-54 \%$ had a higher than secondary education, $72 \%$ were employed and $27 \%$ were married. Nearly all (96\%) the men reported improvement in at least one domain of sexual function, while 19\% reported improvement in all six domains. One-fourth (91/378, $24 \%$ ) of the men reported that at least one domain of sexual function worsened post-VMMC. The most frequently reported domain that worsened was sexual desire $(11 \%)$; in all other domains, $<10 \%$ of the men reported worsening. Men who reported any worsening sexual function were 2.3-fold as likely to be less than 'very satisfied' with the VMMC procedure (risk ratio 2.36, 95\% confidence interval [CI] 1.66-3.34, $p<0.001$ ).

Conclusion: Emphasising improved sexual function experienced after VMMC in demandcreation efforts could potentially increase VMMC uptake in Botswana.

Keywords: Botswana; voluntary medical male circumcision; human immunodeficiency virus (HIV) prevention; men; implementation science; program delivery.

\section{Introduction}

Continued promotion of voluntary medical male circumcision (VMMC) programmes in countries with high human immunodeficiency virus (HIV) burden and low male circumcision rates is needed to decrease population-level HIV incidences. ${ }^{1,2,3}$ More than 18.6 million men have been circumcised through VMMC programmes in 14 priority African countries to date, averting an estimated 230,000 new HIV infections by $2017 ., 5,6,7,8$ Achieving the global target of 27 million more VMMC procedures by 2021, translating to $90 \%$ of males aged 10-29 years being circumcised in priority countries, will depend in part on the continued acceptability of VMMC amongst target populations. ${ }^{3}$ Uptake of VMMC began slowly in Botswana ${ }^{9}$ and has remained modest in spite of government commitment, donor support and availability of service provision of VMMC since 2009. In 2018, Botswana achieved less than $50 \%$ of the country's target of 25000 VMMC procedures. ${ }^{10}$

\section{Project Research Number: IRB\# 42047 | HRDC\# 00699}

Corresponding author: Jillian Pintye, jpintye@uw.edu

Dates: Received: 01 Nov. 2019 | Accepted: 28 Nov. 2019 | Published: 20 Apr. 2020

How to cite this article: Pintye JC, Wirth KE, Ntsuape C, et al. Sexual function after voluntary medical male circumcision for human immunodeficiency virus prevention: Results from a programmatic delivery setting in Botswana. S Afr J HIV Med. 2020;21(1), a1042. https://doi.org/10.4102/sajhivmed.v21i1.1042

Copyright: ( 2020. The Authors. Licensee: AOSIS. This work is licensed under the Creative Commons Attribution License. 
Studies exploring reasons for men's unwillingness to be circumcised have identified concerns related to potential effects of VMMC on sexual function (e.g. erection and orgasm) and sexual pleasure, the risk of surgical pain, reluctance to abstain from sex for at least 6 weeks during recovery and partners' responses. ${ }^{11,12,13}$ A systematic review that included $>40000$ men from cross-sectional, case-control and pre-post circumcision studies concluded that VMMC likely has little or no effect on male sexual function and satisfaction. ${ }^{14}$ However, ascertainment of sexual function data and findings varied across African settings ${ }^{15,16,17}$ and almost no data were included from the context of national VMMC programmes under 'real-world' conditions. One population-based cohort study in Kenya has found that the majority of the men who undergo VMMC are satisfied with the procedure and experience improvement in sexual function that increased over time. ${ }^{18}$ To date, no evaluations have examined sexual function amongst the men who undergo VMMC in Botswana, nor their perceptions of postVMMC satisfaction beyond 7 days. ${ }^{19}$ Gathering evidence on these elements within the local context could inform VMMC messaging tailored to Botswana.

We previously assessed the frequency of adverse events at 7 days and early resumption of sexual intercourse amongst a cohort of adult men who underwent VMMC within a programmatic delivery setting in Botswana. ${ }^{19,20}$ This current analysis examines the post-VMMC experience at 3 months, including sexual function and satisfaction with the procedure. Given the suboptimal uptake of VMMC in Botswana and the concerns of its potentially negative impact on sexual function identified in qualitative studies, ${ }^{21,22}$ these new data could provide valuable evidence for VMMC demand-creation messaging in Botswana.

\section{Methods}

\section{Study design and participants}

We analysed data from a cohort study comprising HIVnegative, sexually active men aged 18-49 years who underwent VMMC through Botswana's National Safe Male Circumcision programme at two government-run clinics in Gaborone, Botswana. Between November 2013 and April 2015 , the parent study enrolled men to prospectively assess sexual behaviours and adverse events following VMMC. ${ }^{19}$ Parent study procedures have been described previously in detail. ${ }^{19}$ Briefly, the study was collaboratively conducted by the Botswana Ministry of Health $(\mathrm{MOH})$ and the International Training and Education Center for Health (I-TECH), a collaboration between the University of Washington and the University of California, San Francisco. After individuals completed group education about the risks and benefits of VMMC and received individual counselling from clinic staff (including HIV testing), they were screened for eligibility and offered enrolment into the study. Study staff collected information on demographic, clinical, relationship and sexual behaviour characteristics at enrolment. All clinical VMMC activities were conducted per $\mathrm{MOH}$ guidelines at no cost to participants and were not part of the study procedures. ${ }^{23}$

\section{Data collection procedures}

After circumcision, follow-up visits were scheduled in alignment with the Botswana $\mathrm{MOH}$ guidelines for adult VMMC (2 days, 7 days, 6 weeks, 3 months and 1 year). ${ }^{23}$ At study visits, participants were asked to self-administer a questionnaire about wound care, patient satisfaction of the procedure and resumption of sexual activities. At 3 months, questionnaire items included assessment of sexual functions. Each study participant was provided with a wallet-size reminder card noting the date of each follow-up visit. Prior to each visit, study staff telephoned participants to remind them of the upcoming scheduled appointment. At each follow-up visit, study staff performed a physical examination, including inspecting the circumcision site, and assessing for signs of sexually transmitted infections (STIs). Participants received BWP100 (approximately USD $\$ 8$ at study initiation) at each visit as reimbursement for time and travel costs. In the event of a missed visit, study staff made telephone calls to reschedule the appointment.

\section{Statistical analysis}

The current analysis on sexual function and satisfaction with the VMMC procedure at 3 months was restricted to men who had data available from 3-month follow-up visits, as data on earlier outcomes from this cohort had previously been reported. ${ }^{23}$ We identified differences between men with and without data on sexual function available at 3-month postVMMC using Chi-square tests for proportions and KruskalWallis test for continuous measures. We assessed satisfaction with the VMMC procedure and the follow-up care using a four-point Likert scale (very satisfied, somewhat satisfied, somewhat dissatisfied and very dissatisfied). We compared the frequency distributions of satisfaction at 7-day and 3-month post-VMMC amongst men who had data available from both time points to describe the changes in satisfaction with the VMMC procedure over time. We assessed whether categories of sexual function improved, had no change or worsened, compared to before undergoing VMMC using a three-point Likert scale (better, no change and worse). Domains of sexual function included sexual desire, ability to put on a condom, ease of vaginal penetration, ease of ejaculation, ability to achieve and maintain an erection, and hygiene/cleanliness. Descriptive statistics were used to summarise the frequency distributions of each sexual function category.

We evaluated the following enrolment characteristics as potential predictors of reporting any worsened sexual function: demographic information (age, education, relationship status, employment, electricity in household) and behaviour (alcohol consumption, age of sexual debut, number sexual partners [lifetime, last 12 months], type of most recent relationship [regular or casual], history of buying sex and condom use) and primary motivation for VMMC (HIV prevention vs. other reasons). Variables were identified as predictors using univariate Poisson regression models with robust error variance, an approach used when the outcome 
prevalence was not rare (e.g. > 10\%). ${ }^{24,25}$ The primary outcome of our Poisson regression models was reporting any worsening of sexual function in any domain since the VMMC procedure at 3-month post-VMMC (yes or no). We included all men with 3-month follow-up data in our primary models regardless of engaging in sexual activity or not, because sexual dysfunction could influence sexual activity. In a sensitivity analysis, we restricted our models to only men who reported sexual activity after undergoing VMMC. We also reran our primary models with the outcome excluding hygiene or cleanliness. We used Stata 15/SE (Stata Corporation, College Station, TX) to perform statistical analyses.

\section{Ethical consideration}

Ethical approvals were obtained from the Health Research and Development Committee at the Botswana Ministry of Health and Wellness (reference number: 00699) as well as the University of Washington Institutional Review Board (reference number: 42047). All participants provided written informed consent for participation in the study in addition to the consent obtained by the clinic staff for the circumcision procedure.

\section{Results}

\section{Baseline characteristics}

In total, 519 who were enrolled in the parent study underwent VMMC (Figure 1). Median age was 27 years (interquartile range [IQR] 23-31), 57\% had completed secondary education or higher and $86 \%$ had electricity in the household, a proxy

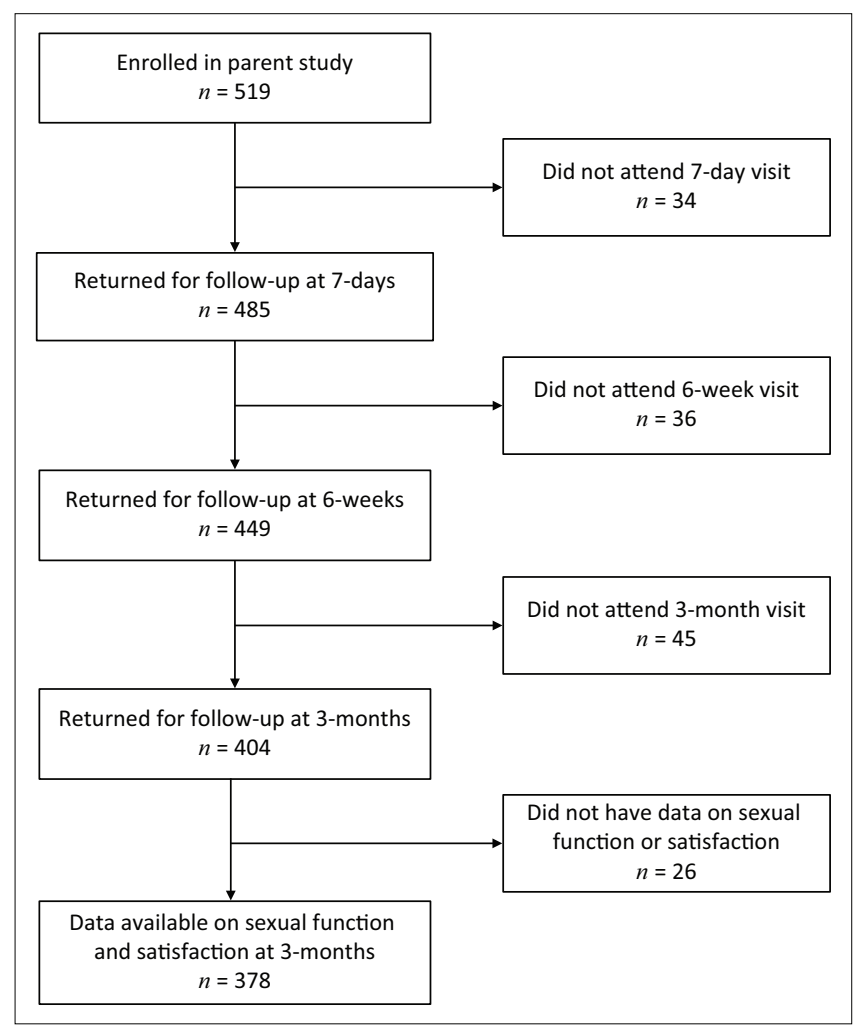

FIGURE 1: Study flowchart for men who underwent voluntary medical male circumcision and were enrolled in the parent study between November 2013 and October 2015. for socio-economic status in this setting. The most common relationship status was dating and not living together (53\%), followed by being married and/or living together $(28 \%)$. Over one-third (37\%) of the men reported having $\geq 6$ drinks at one time at least four times a month. The median age of sexual debut was 19 years (IQR 17-20), 20\% of the men reported having $\geq 2$ sexual partners in the previous month and $21 \%$ reported $\geq 10$ lifetime sexual partners. Almost half (47\%) reported that HIV prevention was their primary reason for becoming circumcised.

Overall, 378/519 (73\%) men had data available on sexual function at 3-month post-VMMC and were included in the final analysis (Figure 1). Of the 141 men without 3-month sexual function data, $82 \%$ attended a prior follow-up visit at 7 days or 6 weeks post-VMMC. Compared with men without data available, men with 3-month post-VMMC sexual function data less frequently had higher than secondary education ( $54 \%$ vs. $66 \%, p=0.005)$. There were no differences in any other baseline characteristics between those who did have and who did not have 3-month data available (Table 1).

\section{Sexual function after voluntary medical male circumcision}

Amongst men with sexual function data available at 3-month post-VMMC ( $n=378)$, the majority $(88 \%)$ reported having sex in the last 90 days. Amongst men who were sexually active in the last 90 days $(n=326)$, the median time since last sex was 7 days (IQR 7-14). Nearly all (96\%) men reported better sexual function in at least one domain; $19 \%$ reported improvement in all six domains. The most frequently reported domain with improvement was hygiene/cleanliness (93\%), followed by ease of vaginal penetration (57\%); $44 \%-$ $50 \%$ of the men reported improvement in all other categories (Figure 2). One-fourth $(91 / 378,24 \%)$ of the men reported worsening sexual function post-VMMC in at least one domain. The most frequently reported domain to worsen was sexual desire (11\%); for all other domains, less than $10 \%$ of the men reported any worsening (Figure 2 ). No change was reported by $36 \%-44 \%$ of the men across all domains except for hygiene/cleanliness (5\%). No baseline

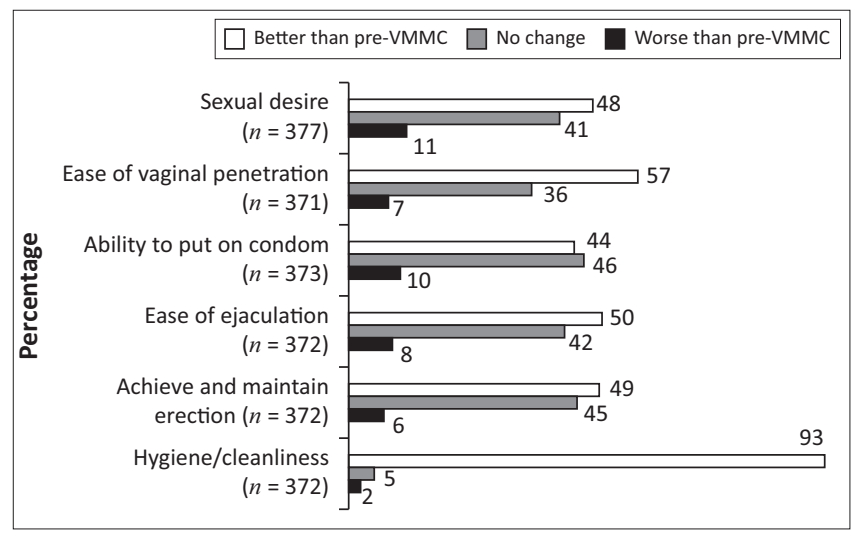

VMMC, voluntary medical male circumcision.

FIGURE 2: Sexual function at 3 months after voluntary medical male circumcision amongst men uninfected by the human immunodeficiency virus $(n=378)$. 
TABLE 1: Baseline characteristics of men who were uninfected by the human immunodeficiency virus who underwent voluntary medical male circumcision, by availability of sexual function data at 3-months after voluntary medical male circumcision.

\begin{tabular}{|c|c|c|c|c|c|c|c|}
\hline \multirow[t]{4}{*}{ Characteristic } & \multicolumn{6}{|c|}{$N(\%)$ of Median (IQR) } & \multirow[t]{4}{*}{$p^{*}, \ddagger$} \\
\hline & \multirow{2}{*}{\multicolumn{2}{|c|}{$\begin{array}{l}\text { Overall } \\
n=519\end{array}$}} & \multicolumn{4}{|c|}{$\begin{array}{l}\text { Sexual function data available } \\
\text { at 3-month post-VMMC }\end{array}$} & \\
\hline & & & \multicolumn{2}{|c|}{$\begin{array}{c}\text { Not available } \\
\quad n=141\end{array}$} & \multicolumn{2}{|c|}{$\begin{array}{c}\text { Available } \\
n=378\end{array}$} & \\
\hline & $n$ & $\%$ & $n$ & $\%$ & $n$ & $\%$ & \\
\hline Age category (years) $(N=519)$ & & & & & & & 0.271 \\
\hline $18-24$ & 167 & 32.2 & 53 & 37.6 & 114 & 30.1 & \\
\hline $25-29$ & 175 & 33.7 & 50 & 35.5 & 125 & 33.1 & \\
\hline $30-34$ & 99 & 19.1 & 22 & 15.6 & 77 & 20.4 & \\
\hline $35-40$ & 54 & 10.4 & 12 & 8.5 & 42 & 11.1 & \\
\hline $40-49$ & 24 & 4.6 & 4 & 2.8 & 20 & 5.3 & \\
\hline Education level $(N=492)$ & & & & & & & $0.005^{*}$ \\
\hline Primary or less & 17 & 3.5 & 7 & 5.4 & 10 & 2.8 & \\
\hline Secondary & 195 & 39.6 & 37 & 28.2 & 158 & 43.8 & \\
\hline Current relationship status $(N=509)$ & & & & & & & 0.990 \\
\hline Single, never married & 94 & 18.5 & 25 & 17.7 & 69 & 18.8 & \\
\hline Married or living together & 140 & 27.5 & 39 & 27.7 & 101 & 27.4 & \\
\hline Dating, not living together & 272 & 53.4 & 76 & 53.9 & 196 & 53.3 & \\
\hline Separated, divorced or widowed & 3 & 0.6 & 1 & 0.7 & 2 & 0.5 & \\
\hline Employed $(N=509)$ & & & & & & & 0.450 \\
\hline No & 150 & 29.5 & 45 & 31.9 & 105 & 28.5 & \\
\hline Yes & 359 & 70.5 & 96 & 68.1 & 263 & 71.5 & \\
\hline Electricity in household $(N=509)$ & & & & & & & 0.890 \\
\hline No & 74 & 14.5 & 20 & 14.2 & 54 & 14.7 & \\
\hline Yes & 435 & 85.5 & 121 & 85.8 & 314 & 85.3 & \\
\hline Drinks alcohol $(N=509)$ & & & & & & & 0.750 \\
\hline No & 197 & 38.7 & 53 & 37.6 & 144 & 39.1 & \\
\hline Yes & 312 & 61.3 & 88 & 62.4 & 224 & 60.9 & \\
\hline Has $\geq 6$ drinks at least four times a month $(N=508)$ & & & & & & & 0.550 \\
\hline Yes & 189 & 37.2 & 55 & 39.3 & 134 & 36.4 & \\
\hline Age at sexual debut, years $(N=502)$ & 19.0 & $17.0-20.0$ & 19.0 & $17.0-20.0$ & 19.0 & $17.0-21.0$ & 0.310 \\
\hline No. of sex partners (last month) $(N=461)$ & & & & & & & 0.170 \\
\hline None & 153 & 33.2 & 38 & 30.2 & 115 & 34.3 & \\
\hline 1 partner & 217 & 47.1 & 56 & 44.4 & 161 & 48.1 & \\
\hline $2+$ partners & 91 & 19.7 & 32 & 25.4 & 59 & 17.6 & \\
\hline No. of lifetime sex partners $(N=470)$ & & & & & & & 0.950 \\
\hline 1 partner & 52 & 11.1 & 16 & 12.2 & 36 & 10.6 & \\
\hline 2-4 partners & 168 & 35.7 & 45 & 34.4 & 123 & 36.3 & \\
\hline 5-10 partners & 151 & 32.1 & 43 & 32.8 & 108 & 31.9 & \\
\hline $10+$ partners & 99 & 21.1 & 27 & 20.6 & 72 & 21.2 & \\
\hline Most recent sexual partner type $(N=459)$ & & & & & & & 0.430 \\
\hline Casual & 49 & 10.7 & 16 & 12.5 & 33 & 10.0 & \\
\hline Regular & 410 & 89.3 & 112 & 87.5 & 298 & 90.0 & \\
\hline Always uses condom with regular partner $(N=299)$ & & & & & & & 0.900 \\
\hline No & 158 & 52.8 & 47 & 53.4 & 111 & 52.6 & \\
\hline Yes & 141 & 47.2 & 41 & 46.6 & 100 & 47.4 & \\
\hline Always uses condom with casual partner ( $N=199)$ & & & & & & & 0.870 \\
\hline No & 57 & 28.6 & 17 & 27.9 & 40 & 29.0 & \\
\hline Yes & 142 & 71.4 & 44 & 72.1 & 98 & 71.0 & \\
\hline History of buying sex (last year) $(N=468)$ & & & & & & & 0.690 \\
\hline No & 435 & 93.0 & 118 & 92.2 & 317 & 93.2 & \\
\hline Yes & 33 & 7.0 & 10 & 7.8 & 23 & 6.8 & \\
\hline Primary reason for VMMC $(N=509)$ & & & & & & & 0.220 \\
\hline Non-HIV reason & 270 & 53.0 & 81 & 57.4 & 189 & 51.4 & \\
\hline HIV prevention & 239 & 47.0 & 60 & 42.6 & 179 & 48.6 & \\
\hline
\end{tabular}

VMMC, voluntary medical male circumcision; IQR, interquartile range; HIV, human immunodeficiency virus.

\pm Kruskal-Wallis test for continuous measures and Chi-square test for proportions were used to detect differences in baseline characteristics between men with and without data available on sexual function at 3-month post-VMMC.

$*, p<0.05$. 
demographic, clinical or behavioural characteristics were predictive of worsening sexual function (Table 2); results were very similar in models restricted to sexually active men and when excluding hygiene/cleanliness from the domains included in the outcome (data not shown).

\section{Satisfaction with voluntary medical male circumcision procedure}

Overall, $84 \%$ of men were very satisfied with the VMMC procedure at 3 months, $14 \%$ were somewhat satisfied, $1 \%$ were somewhat dissatisfied and $1 \%$ were very dissatisfied. Frequency of being very satisfied with the VMMC procedure was slightly lower at 3 months, compared with 7-day postVMMC procedure (Figure 3, $84 \%$ vs. $90 \%, p=0.004$ ). Almost all $(93 \%)$ of the men reported being very satisfied with follow-up care at 3 months (Figure 4). Amongst men who were very satisfied with VMMC at 7 days and became less satisfied/dissatisfied at 3 months $(n=23), 17 \%$ reported worsening sexual function. At 3 months, men who reported any worsening of sexual function were 2.3-fold as likely to be less than 'very satisfied' with the VMMC procedure at 3 months (risk ratio 2.36, 95\% confidence interval [CI] 1.66$3.34, p<0.001)$. Amongst men who were overall somewhat or very dissatisfied with VMMC at 3 months $(n=7)$, nonmutually exclusive reasons for being dissatisfied included appearance $(n=4)$, wound care requirements $(n=2)$, aspects of the procedure $(n=3)$ and issues with pain $(n=2)$.

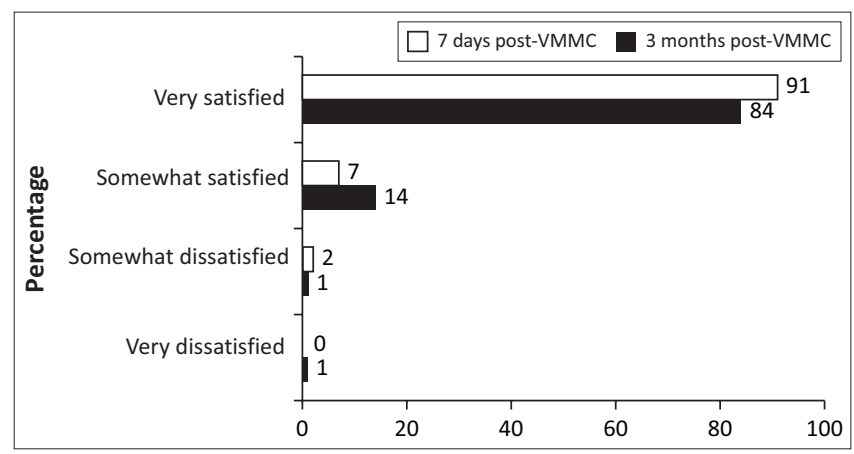

VMMC, voluntary medical male circumcision.

FIGURE 3: Satisfaction with voluntary medical male circumcision procedure at 7 days and 3 months after voluntary medical male circumcision amongst men who had data available at both time points $(n=375)$.

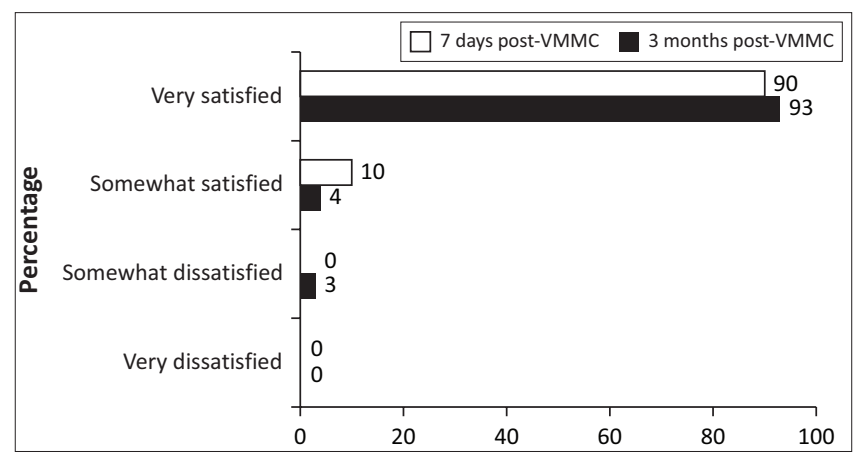

VMMC, voluntary medical male circumcision.

FIGURE 4: Satisfaction with voluntary medical male circumcision follow-up care at 7 days and 3 months after voluntary medical male circumcision amongst men who had data available at both time points $(n=375)$.

\section{Discussion}

In this longitudinal evaluation of the men who became circumcised within a programmatic VMMC setting in Botswana, we found very high overall satisfaction with the procedure at 3 months after VMMC accompanied by frequently reported improvement in sexual function. Consistent with prior data from research settings, our implementation evaluation found that nearly all (98\%) men were at least somewhat satisfied overall with the VMMC procedure; almost one-fifth (19\%) reported improved sexual function in every category assessed; and over one-third reported no change. ${ }^{26}$ Although few men reported being dissatisfied with VMMC, frequency of worsening sexual function post-VMMC was higher in this group. Our results highlight considerations for demand-creation messaging as VMMC programmes continue to roll out in countries such as Botswana that have high HIV burden and modest VMMC uptake.

Similar to prior studies that evaluated sexual function preand post-circumcision amongst African men, ${ }^{15,18}$ we found that the majority of the men reported improvement in some domains of sexual function after undergoing VMMC in Botswana. When asked to retrospectively compare with the condition before undergoing VMMC, approximately half of the men in our evaluation reported improved sexual desire, ease of vaginal penetration and ejaculation, and/or ability to achieve and maintain an erection post-VMMC. Studies amongst men who became circumcised in adulthood are especially useful in evaluating the impact of VMMC on sexual function because these men served as their own control. $^{14}$ Data from randomised trials in Uganda and Kenya ${ }^{15,16}$ provide the highest quality evidence on the effects of VMMC on sexual function and found some improvement in sexual function after VMMC. There are important contextual differences between men who were willing to enrol in the early VMMC trials, when efficacy was unknown and VMMC was randomly assigned, and those who selfselect VMMC delivered as part of national programmes. Our findings contribute to the evidence base supporting the benefits of VMMC in programmatic settings extended beyond HIV prevention and could broadly improve sexual health amongst African men. ${ }^{17}$ The future programmatic evaluations could improve design rigour by assessing sexual function prior to undergoing VMMC and comparing it with post-VMMC assessment.

In spite of the high levels of improvement in sexual function following VMMC, an appreciable proportion (19\%) of the men in our evaluation reported at least one category of sexual function worsening after VMMC. A systematic review published in 2013 by Morris and Krieger ${ }^{14}$ that included 20931 circumcised men and 19542 uncircumcised men found no evidence for differences in any component of sexual function by circumcision status. However, almost no data were included from programmatic delivery settings in African countries that could provide different quality of services or reach a population unlike men enrolled in the initial VMMC randomised trials. ${ }^{15,16}$ In addition, prior 
TABLE 2:Predictors of reporting worse sexual function in any category at 3 months after voluntary medical male circumcision, compared to pre-voluntary medical male circumcision amongst men uninfected by the human immunodeficiency virus who underwent voluntary medical male circumcision $(n=378)$. $\dagger, \pm$

\begin{tabular}{|c|c|c|c|c|c|c|c|}
\hline \multirow[t]{3}{*}{ Characteristic } & \multicolumn{4}{|c|}{ Worse sexual function at $\mathbf{3}$ months: } & \multicolumn{3}{|c|}{ Univariate Poisson Regression models } \\
\hline & \multicolumn{2}{|c|}{$\begin{array}{c}\text { No } \\
n=281\end{array}$} & \multicolumn{2}{|c|}{$\begin{array}{c}\text { Yes } \\
n=97\end{array}$} & \multirow[t]{2}{*}{ Crude RR } & \multirow[t]{2}{*}{$95 \% \mathrm{Cl}$} & \multirow[t]{2}{*}{$p^{*}$} \\
\hline & $n$ & $\%$ & $n$ & $\%$ & & & \\
\hline \multicolumn{8}{|l|}{ Age } \\
\hline $18-30$ years & 181 & 63.1 & 58 & 63.7 & 1.37 & $0.76-2.45$ & 0.291 \\
\hline $30-34$ years & 55 & 19.1 & 22 & 24.2 & 1.61 & $0.85-3.06$ & 0.146 \\
\hline $34-49$ years & 51 & 17.8 & 11 & 12.1 & Ref. & - & - \\
\hline No & 130 & 46.9 & 38 & 45.2 & Ref. & - & - \\
\hline Yes & 147 & 53.1 & 46 & 54.8 & 1.05 & $0.72-1.54$ & 0.786 \\
\hline \multicolumn{8}{|c|}{ Has regular partner } \\
\hline No & 24 & 9.4 & 9 & 12.0 & Ref. & - & - \\
\hline Yes & 232 & 90.6 & 66 & 88.0 & 0.96 & $0.66-1.39$ & 0.827 \\
\hline \multicolumn{8}{|l|}{ Married§ } \\
\hline No & 260 & 92.5 & 79 & 90.8 & Ref. & - & - \\
\hline \multicolumn{8}{|c|}{ Lives together with partnerq } \\
\hline No & 208 & 74.0 & 60 & 69.0 & Ref. & - & - \\
\hline Yes & 73 & 26.0 & 27 & 31.0 & 1.21 & $0.81-1.79$ & 0.349 \\
\hline \multicolumn{8}{|l|}{ Employed } \\
\hline No & 81 & 28.8 & 24 & 27.6 & Ref. & - & - \\
\hline Yes & 200 & 71.2 & 63 & 72.4 & 1.05 & $0.69-1.58$ & 0.824 \\
\hline \multicolumn{8}{|c|}{ Electricity in household } \\
\hline No & 42 & 14.9 & 12 & 13.8 & Ref. & - & - \\
\hline Yes & 239 & 85.1 & 75 & 86.2 & 1.07 & $0.63-1.84$ & 0.792 \\
\hline \multicolumn{8}{|l|}{ Drinks alcohol } \\
\hline No & 114 & 40.6 & 30 & 34.5 & Ref. & - & - \\
\hline Yes & 167 & 59.4 & 57 & 65.5 & 1.22 & $0.83-1.80$ & 0.315 \\
\hline \multicolumn{8}{|c|}{ Has $\geq 6$ drinks at least four times a month } \\
\hline No & 175 & 62.3 & 59 & 67.8 & Ref. & - & - \\
\hline$<19$ years & 131 & 47.5 & 37 & 43.5 & Ref. & - & - \\
\hline$\geq 19$ years & 145 & 52.5 & 48 & 56.5 & 1.13 & $0.78-1.64$ & 0.526 \\
\hline No. of sex partn & & & & & & & \\
\hline$<2$ partners & 217 & 84.1 & 59 & 76.6 & Ref. & - & - \\
\hline$\geq 2$ partners & 41 & 15.9 & 18 & 23.4 & 1.43 & $0.91-2.23$ & 0.119 \\
\hline No. of lifetime se & & & & & & & \\
\hline$<5$ partners & 120 & 46.9 & 39 & 47.0 & Ref. & - & - \\
\hline$\geq 5$ partners & 136 & 53.1 & 44 & 53.0 & 1.00 & $0.68-1.45$ & 0.986 \\
\hline Most recent sext & & & & & & & \\
\hline Casual & 24 & 9.4 & 9 & 12.0 & Ref. & - & - \\
\hline Regular & 232 & 90.6 & 66 & 88.0 & 0.81 & $0.45-1.48$ & 0.495 \\
\hline Inconsistent or $n$ & & & & & & & \\
\hline No & 84 & 51.9 & 27 & 55.1 & Ref. & - & - \\
\hline Yes & 78 & 48.1 & 22 & 44.9 & 0.90 & $0.55-1.48$ & 0.691 \\
\hline Inconsistent or $\mathrm{n}$ & & & & & & & \\
\hline No & 29 & 30 & 11 & 26 & Ref. & - & - \\
\hline Yes & 67 & 70 & 31 & 74 & 1.15 & $0.64-2.06$ & 0.638 \\
\hline History of buying & & & & & & & \\
\hline No & 246 & 93.5 & 71 & 92.2 & Ref. & - & - \\
\hline Yes & 17 & 6.5 & 6 & 7.8 & 1.16 & $0.57-2.39$ & 0.678 \\
\hline Primary reason $\mathrm{f}$ & & & & & & & \\
\hline Non-HIV reason & 141 & 50.2 & 48 & 55.2 & Ref. & - & - \\
\hline HIV prevention & 140 & 49.8 & 39 & 44.8 & 0.86 & $0.59-1.24$ & 0.417 \\
\hline
\end{tabular}

$\mathrm{RR}$, risk ratio; $\mathrm{VMMC}$, voluntary medical male circumcision; $\mathrm{Cl}$, confidence interval.

$\dagger$, Includes men who had data available on sexual function at 3-month post-VMMC procedure.

$\mp$. Having worse sexual function at 3-month post-VMMC, compared to pre-VMMC in any of the following categories: sexual desire, ease of vaginal penetration, ability to put on a condom, ease of ejaculation, achieve and maintain erection, hygiene/cleanliness.

$\S$, Includes married men who live or do not live with their wives.

I, Includes married men who live with their wives or unmarried men who live with their partners.

$*, p<0.05$; Wald test $p$-value for categorical variables. 
randomised trials ${ }^{15,16}$ assessed prevalence of sexual dysfunctional components (erectile dysfunction, ease of ejaculation, etc.) up to 24 months post-VMMC and found a decrease in dysfunction over time. In our programmatic evaluation, we asked participants to retrospectively report changes in sexual functioning, if any, at the 3-month followup visit (as opposed to conducting a separate assessment of sexual functioning at baseline). Men who were less satisfied with the VMMC procedure were also more likely to report worsening of sexual function. Men currently experiencing sexual dysfunction may be more likely to report that their status had worsened after VMMC because of recall bias. It is also possible that men enrolled in our evaluation could experience better sexual function at later time points. We also found modestly lower, although still very high, satisfaction with the VMMC procedure at 3 months (84\%), compared to 7-day (90\%) post-VMMC. To our knowledge, no other programmatic evaluations amongst African men have evaluated satisfaction with VMMC over time. The future programmatic evaluations could identify areas for improving the VMMC procedure, counselling and follow-up care to prevent potential negative effects on sexual function and satisfaction with the procedure.

Over a decade after initiation, uptake of VMMC in Botswana's national programme remains modest. ${ }^{10}$ A recent systematic review from July 2019 by Ensor et al. has found that the most effective VMMC demand-creation interventions are financial incentives and education or counselling programmes delivered by community opinion leaders or individuals with personal experience of VMMC. ${ }^{27}$ To date, no VMMC demand-creation intervention studies have been conducted in Botswana and ongoing mass media campaigns focus on protection against HIV associated with VMMC. The future demand-creation messages in Botswana could be tailored to the values and preferences of the men at risk of HIV infection whilst extending beyond HIV prevention. ${ }^{28,29}$ Integrating evidence for improved sexual function and satisfaction following VMMC into mainstream messaging could potentially motivate Batswana men, who may not perceive their own HIV risk or for whom HIV prevention is not a motivator for VMMC, to seek VMMC. Our evaluation found high frequency of improved sexual function and overall satisfaction with VMMC within programmatic settings, which could be helpful for framing the holistic benefits of VMMC in future messaging.

Our study has limitations. We only ascertained sexual function information at 3-month post-VMMC and retrospectively asked men to compare aspects of sexual function with their pre-VMMC experiences. This approach was intended to capture how VMMC impacts sexual function, although a baseline assessment of sexual function would have improved the rigour of our findings. Recall bias is possible with overreporting of worsening sexual function amongst dissatisfied men or potentially choice-supportive bias of improved function to rationalise the decision to undergo VMMC. Not all men returned for follow-up and/or had data on sexual function available at 3-month post-VMMC. This may bias our overall estimates of satisfaction and sexual function. We detected minimal baseline differences between men with and without 3-month data available, and no characteristics were predictive of worsening sexual function. Men who did not return for follow-up visits could potentially be more or less satisfied with their VMMC experience, which could bias our results. We intentionally conducted an implementation evaluation without intensive follow-up tracing to align with programmatic settings. The future evaluations could include more research procedures such as at-home follow-up tracing to collect data that are more complete.

\section{Conclusion}

To date, demand-creation messaging for VMMC in Botswana has primarily focussed on HIV prevention. However, as VMMC uptake remains modest amongst Batswana men, there is a need to effectively promote VMMC to men at-risk of HIV infection for whom protection against HIV may not be a motivator to undergo VMMC. Similar to prior studies from research settings in other African countries, our programmatic data show that the majority of the men report improved sexual function across multiple categories and high overall satisfaction after VMMC. As VMMC continues to roll out in Botswana, incorporating evidence of other nonHIV-related benefits of VMMC into demand-creation messaging may support maximising VMMC uptake.

\section{Acknowledgements}

The authors are grateful to all the participants for their participation in the study.

\section{Competing interests}

The authors have declared that no competing interest exists.

\section{Authors' contributions}

All authors contributed equally to this work.

\section{Funding information}

This work was supported by the President's Emergency Plan for AIDS Relief (PEPFAR) through grant No. U91HA06801 from the US Department of Health and Human Services, Health Resources and Services Administration (HRSA), HIV / AIDS Bureau's Global Health Systems Branch.

\section{Data availability statement}

Data sharing is not applicable to this article as no new data were created or analysed in this study.

\section{Disclaimer}

The views and opinions expressed in this article are those of the authors and do not necessarily reflect the official policy or position of any affiliated agency of the authors. 


\section{References}

1. Tobian AA, Kacker S, Quinn TC. Male circumcision: A globally relevant but underutilized method for the prevention of HIV and other sexually transmitted infections. Annu Rev Med. 2014;65:293-306. https://doi.org/10.1146/annurevmed-092412-090539

2. Grabowski MK, Serwadda DM, Gray RH, et al. HIV prevention efforts and incidence of HIV in Uganda. N Engl J Med. 2017;377(22):2154-2166. https://doi.org/ 10.1056/NEJMoa1702150

3. Joint United Nations Programme on HIV/AIDS (UNAIDS). Policy brief. A framework for voluntary medical male circumcision: Effective HIV prevention and a gateway to improved adolescent boys' and men's health in eastern and southern Africa by 2021. Geneva: World Health Organisation; 2016

4. World Health Organisation (WHO). WHO progress brief. Voluntary medical male circumcision for HIV prevention. Geneva: World Health Organization; 2018.

5. Hines JZ, Ntsuape OC, Malaba K, et al. Scale-up of voluntary medical male circumcision services for HIV prevention -12 countries in southern and eastern Africa, 2013-2016. MMWR Morb Mortal Wkly Rep. 2017;66(47):1285-1290. Africa, 2013-2016. MMWR Morb Mortal
https://doi.org/10.15585/mmwr.mm6647a2

6. Davis SM, Hines JZ, Habel $M$, et al. Progress in voluntary medical male circumcision for HIV prevention supported by the US President's Emergency Plan for AIDS Relief through 2017: Longitudinal and recent cross-sectional programme data. BMJ Open. 2018;8(8):e021835. https://doi.org/10.1136/ programme data. BM

7. Bochner AF, Baeten JM, Rustagi AS, et al. A cross-sectional analysis of Trichomonas vaginalis infection among heterosexual HIV-1 serodiscordant African couples. Sex Transm Infect. 2017;93(7):520-529. https://doi.org/10.1136/sextrans-2016-053034

8. Pintye J, Drake AL, Unger JA, et al. Male partner circumcision associated with lower Trichomonas vaginalis incidence among pregnant and postpartum Kenyan women: A prospective cohort study. Sex Transm Infect. 2017;93(2):137-143. https://doi.org/10.1136/sextrans-2016-052629

9. Sabone M, Magowe M, Busang L, Moalosi J, Binagwa B, Mwambona J, Impediments for the uptake of the Botswana government's male circumcision initiative for HIV prevention. Sci World J. 2013;2013:387508. https://doi. org/10.1155/2013/387508

10. United States Department of State. FY 2019 PEPFAR planned allocation and strategic direction [homepage on the Internet]. Washington, DC;2019 [cited 2019 January 16]. Available from: https://www.pepfar.gov/documents/organization/289946.pdf

11. Westercamp M, Bailey RC, Bukusi EA, Montandon M, Kwena Z, Cohen CR. Male circumcision in the general population of Kisumu, Kenya: Beliefs about protection risk behaviors, HIV, and STIs. PLoS One. 2010;5(12):e15552. https://doi.org/ 10.1371/journal.pone.0015552

12. Toefy Y, Skinner D, Thomsen SC. 'What do you mean i've got to wait for six weeks?!' Understanding the sexual behaviour of men and their female partners after voluntary medical male circumcision in the Western Cape. PLoS One. 2015;10(7):e0133156. https://doi.org/10.1371/journal.pone.0133156

13. Rogers JH, Odoyo-June E, Jaoko W, Bailey RC. Time to complete wound healing in HIV-positive and HIV-negative men following medical male circumcision in Kisumu, Kenya: A prospective cohort study. PLoS One. 2013;8(4):e61725. https://doi.org/10.1371/journal.pone.0061725

14. Morris BJ, Krieger JN. Does male circumcision affect sexual function, sensitivity, or satisfaction? - A systematic review. J Sex Med. 2013;10(11):2644-2657. https://doi.org/10.1111/jsm.12293
15. Krieger JN, Mehta SD, Bailey RC, et al. Adult male circumcision: Effects on sexual function and sexual satisfaction in Kisumu, Kenya. J Sex Med. 2008;5(11):2610-2622. https://doi.org/10.1111/j.1743-6109.2008.00979.x

16. Kigozi G, Watya $S$, Polis $C B$, et al. The effect of male circumcision on sexual satisfaction and function, results from a randomized trial of male circumcision for human immunodeficiency virus prevention, Rakai, Uganda BJU Int 2008;101(1):65-70. https://doi.org/10.1111/j.1464-410X.2007.07369.x

17. Zulu R, Jones D, Chitalu N, Cook R, Weiss S. Sexual satisfaction, performance, and partner response following voluntary medical male circumcision in Zambia: The spear and shield project. Glob Health Sci Pract. 2015;3(4):606-618. https://doi.org/10.9745/GHSP-D-15-00163

18. Nordstrom MP, Westercamp N, Jaoko W, Okeyo T, Bailey RC. Medical male circumcision is associated with improvements in pain during intercourse and sexual satisfaction in Kenya. J Sex Med. 2017;14(4):601-612. https://doi.org/ 10.1016/j.jsxm.2017.02.014

19. Wirth KE, Semo BW, Spees LP, Ntsuape C, Barnhart S, Ledikwe JH. A prospective cohort study of safety and patient satisfaction of voluntary medical male circumcision in Botswana. PLoS One. 2017;12(11):e0185904. https://doi.org/ 10.1371/journal.pone. 0185904

20. Pintye J, Wirth KE, Ntsuape C, et al. Early resumption of sex after voluntary medical male circumcision for HIV prevention within a programmatic delivery setting in Botswana. Int J STD AIDS. 2019;30(3):1275-1283. https://doi.org/ 10.1177/0956462419866051

21. Green LW, Travis JW, McAllister RG, Peterson KW, Vardanyan AN, Craig A. Male circumcision and HIV prevention insufficient evidence and neglected externa validity. Am J Prev Med. 2010;39(5):479-482. https://doi.org/10.1016/j. amepre.2010.07.010

22. Wamai RG, Morris BJ, Bailey RC, Klausner JD, Boedicker MN. Male circumcision for protection against HIV infection in sub-Saharan Africa: The evidence in favour justifies the implementation now in progress. Glob Public Health. 2015;10 (5-6):639-666. https://doi.org/10.1080/17441692.2014.989532

23. Ministry of Health. Safe male circumcision: Additional strategy for HIV prevention: A national strategy. Gaborone: Ministry of Health; 2010.

24. Breslow NE. Generalized linear models: Checking assumptions and strengthening conclusions. Statistica Applicata. 1996;8(1):23-41

25. Lee J, Chia KS. Estimation of prevalence rate ratios for cross-sectional data: An example in occupational epidemiology. Br J Ind Med. 1993;50(9):861-862. https://doi.org/10.1136/oem.50.9.861

26. Herman-Roloff A, Bailey RC, Agot K. Factors associated with the early resumption of sexual activity following medical male circumcision in Nyanza province, Kenya. AIDS Behav. 2012;16(5):1173-1181. https://doi.org/10.1007/s10461011-0073-1

27. Ensor S, Davies B, Rai T, Ward H. The effectiveness of demand creation interventions for voluntary male medical circumcision for HIV prevention in subSaharan Africa: A mixed methods systematic review. J Int AIDS Soc. 2019;22 (Suppl 4):e25299. https://doi.org/10.1002/jia2.25299

28. Ledikwe JH, Nyanga RO, Hagon J, Grignon JS, Mpofu M, Semo BW. Scaling-up voluntary medical male circumcision - What have we learned? HIV AIDS (Auckl) 2014;6:139-146. https://doi.org/10.2147/HIV.S65354

29. Gurman TA, Dhillon P, Greene JL, Makadzange P, Khumlao P, Shekhar N. Informing the scaling up of voluntary medical male circumcision efforts through the use of theory of reasoned action: Survey findings among uncircumcised young men in Swaziland. AIDS Educ Prev. 2015;27(2):153-166. https://doi.org/10.1521/ aeap.2015.27.2.153 